\title{
RELAÇÃO DE ATRIBUTOS DO SOLO COM A AGREGAÇÃO DE UM LATOSSOLO VERMELHO SOB SISTEMAS DE PREPARO E PLANTAS DE VERÃO PARA COBERTURA DO SOLO ${ }^{(1)}$
}

\author{
J ackson Adriano Albuquerque ${ }^{(2)}$, J eferson Argenton(3), Cimélio \\ Bayer $^{(4)}$, Leandro do Prado Wildner ${ }^{(5)} \&$ Márcio \\ Alekssander Granzotto Kuntze ${ }^{(6)}$
}

\begin{abstract}
RESUMO
O preparo de solo e as espécies vegetais que compõem o sistema de rotação de culturas têm expressivo efeito na qualidade física do solo, principalmente na estabilidade de agregados. Neste estudo, objetivou-se avaliar a estabilidade dos agregados de um solo cultivado com preparo reduzido (PR) e preparo convencional (PC) com utilização de plantas de cobertura. Dois experimentos foram efetuados em Chapecó (SC), num Latossolo Vermel ho distroférrico em PR (1993-1998) e PC (1994-1998), nos quais foram avaliados cinco sistemas de cultura: milho + guandu anão; milho + mucuna cinza; milho + feijão-de-porco; milho + soja preta e milho isolado. 0 uso do solo degradou suas propriedades físicas, comparativamente ao sistema com mata nativa, reduziu o teor de C orgânico (CO) e a estabilidade dos agregados. As plantas de cobertura de verão aumentaram o teor de CO; entretanto, não modificaram o grau de floculação de argila e a estabilidade de agregados, quando comparadas às do sistema milho isolado. A recuperação de solos degradados por meio do uso de plantas de cobertura foi mais efetiva quando estas foram associadas ao preparo reduzido, evidenciando a importância de sistemas de manejo com baixo revolvimento e alto aporte de resíduos vegetais para aumentar o CO do solo.
\end{abstract}

Termos de indexação: manejo de solo, plantas de cobertura do solo, floculação da argila, qualidade física.

\footnotetext{
(1) Parte da Tese de Mestrado, apresentada ao Curso de Pós-Graduação em Ciência do Solo - Universidade do Estado de Santa Catarina - UDESC. Recebido para publicação em julho de 2003 e aprovado em abril de 2005.

(2) Professor do Departamento de Solos, Universidade do Estado de Santa Catarina - UDESC. Caixa Posta 281, CEP 88520-000 Lages (SC). Pesquisador do CNPq. E-mail: a2ja@cav.udesc.br

(3) Mestre em Ciência do Solo, UDESC. E-mail: jargenton@fischerfraburgo.com.br

(4) Professor do Departamento de Solos da Universidade Federal do Rio Grande do Sul - UFRGS. Caixa Postal 15100, CEP 90001970 Porto Alegre (RS). Pesquisador do CNPq. E-mail: cimelio.bayer@ufrgs.br

(5) Pesquisador do Centro de Pesquisa para Agricultura Familiar - EPAGRI. Caixa Postal 791, CEP $89901-970$ Chapecó (SC). E-mail: Ipwild@epagri.rct-sc.br

(6) Graduando do Curso de Agronomia, UDESC.
} 


\title{
SUMMARY: RELATIONSHIP OF SOIL ATTRIBUTES WITH AGGREGATE STABILITY OF A HAPLUDOX UNDER DISTINCT TILLAGE SYSTEMS AND SUMMER COVER CROPS
}

\begin{abstract}
Tillageand plant species that composethesoil management and crop rotation systems have a pronounced effect on soil physical quality, especially on aggregate stability. This study aimed to evaluate the degree of aggregatestability of a soil cultivated under reduced tillage (RT) and conventional tillage (CT) using distinct summer cover crops. Two experiments were carried out in Chapecó, State of Santa Catarina, Brazil on a Hapludox under RT (1993-1998) and CT (1994-1998). Five crop systems were evaluated in each tillagesystem: maize + Cajanus cajan (pigeon pea), maize +Stil ozobiun niveum (mucuna), maize + Canavalia ensiformis (jack bean), maize + Glycine sp (black soybean), and single maize. Compared to the nativeforest, cultivation degraded thesoil physical properties. It reduced theaggregatestability and organic carbon concentration. Thesummer cover crops increased theorganic carbon concentration, but had no effect on thedegree of clay flocculation and aggregatestability. Soil recovery by cover crops was more effecti vewhen using reduced tillage, evidencing the importance of management systems of low soil mobilization and high input of plant residues to increase organic carbon.
\end{abstract}

Index terms: soil management, cover crops, clay flocculation, soil physical quality.

\section{INTRODUÇÃO}

O solo sob vegetação nativa encontra-se, normalmente, em melhor estado de agregação ecom teor estável dematéria orgânica. Sua utilização para fins agrícolas, com a introdução das práticas de cultivo, altera as propriedades físicas, químicas e biológicas desse solo, principalmente o teor da matéria orgânica, a atividade e população microbiana e a estabilidade estrutural (Campos et al., 1995).

O revolvimento do solo, em muitos casos necessário por causa da compactação, elimina as plantas espontâneas e rearranja as partículas do solo, resultando numa maior aeração e infiltração de água logo após o preparo e nos estádios iniciais de crescimento e desenvolvimento das culturas, principal mente em sol os compactados. No entanto, reduz a estabilidade de agregados, principalmente dos macroagregados (Alvarenga et al., 1986), o que é mais evidente em solos arenosos (Albuquerque et al., 1996), aumentando os riscos à erosão hídrica (Sidiras et al., 1984).

Por sua vez, sistemas de preparo que revolvem menos o solo e acumulam resíduos culturais na superfície preservam sua estrutura e retêm mais água na camada superficial (Sidiras et al., 1984), principalmente pelo aumento da matéria orgânica e da mi croporosidade (Castro Filho et al., 1998). Por esse motivo, processos como a infiltração e a evaporação de água do solo também são alterados (Sidiras et al., 1984; Hillel, 1998).

Em Latossol o Vermel ho distrófico, Oliveira et al . (2004) observaram que a estabilidade de agregados no sistema Cerrado foi reduzida pelo preparo convencional, enquanto o plantio direto recuperou parte da estabilidade perdi da pelo preparo intensivo, possivelmente, pelo maior teor de CO. Entretanto, dado o menor revolvimento, esses sistemas podem aumentar a densidade do sol o na camada superficial (Albuquerque et al., 2001), embora este comportamento nem sempre seja observado (Albuquerque et al., 1995; Costa et al., 2003; Oliveira et al., 2003).

Em sistemas conservacionistas demanejo de solo, o uso de plantas de cobertura apresenta-se como uma prática básica, pois protege a superfície contra os agentes erosivos (Schick et al., 2000), adiciona ao solo $\mathrm{C}$ fotossintetizado e $\mathrm{N}$ fixado biologicamente (Amado \& Mielniczuk, 2000), recicla nutrientes e melhora a estabilidade da estrutura (Alvarenga et al., 1986), além de destacar o efeito físico das raízes sobre a formação e manutenção dos agregados do sol o (Tisdall \& Oades, 1982; M unner \& Oades, 1989; Silva \& Mielniczuk, 1997; Silva et al., 1998). Nos sistemas de manejo que utilizam plantas de cobertura, as gramíneas perenes apresentam ação agregante mais prolongada do que as leguminosas (Carpenedo \& Mielniczuk, 1990; Paladini \& Mielniczuk, 1991; Silva et al., 1998), graças à presença de um sistema radicular fasciculado, mais denso, com maior contato com as partículas do solo. Segundo Borges et al . (1994), porém, as leguminosas anuais de inverno têm um efeito em curto prazo mais efetivo do que as gramíneas, pois apresentam uma relação $\mathrm{C} / \mathrm{N}$ baixa, favorável à rápida decomposição microbiana.

Este estudo objetivou avaliar a estabilidade dos agregados de um Latossolo Vermel ho distroférrico 
cultivado com preparo reduzido e convencional com utilização de plantas de cobertura.

\section{MATERIAL E MÉTODOS}

Este estudo foi realizado no Centro de Pesquisa para Agricultura Familiar (Cepaf) da Empresa de Pesquisa Agropecuária e Extensão Rural de Santa Catarina S.A. - EPAGRI - em Chapecó (SC), em um Latossolo Vermelho distroférrico muito argiloso, derivado de basalto, com $65 \mathrm{~g} \mathrm{~kg}^{-1}$ de areia, 265 de silte e 670 de argila. A declividade média do local é de $0,10 \mathrm{~m} \mathrm{~m}^{-1}$. A fração argila é composta por caulinita e, em menor teor, por hematita e goethita (Argenton, 2000). O clima da região é do tipo mesotérmico úmido com verão quente (Cfa) (Santa Catarina, 1986). A precipitação pluvial anual é de $2.039 \mathrm{~mm}$, variando de $183 \mathrm{~mm}$ em janeiro a $148 \mathrm{~mm}$ em agosto. A temperatura média anual é de $18,1^{\circ} \mathrm{C}$, variando mensal mente de 14,1 a $23,0{ }^{\circ} \mathrm{C}$.

Foram realizados dois experimentos, ambos adjacentes a uma mata nativa, a qual se considerou como condição original do solo. Antes da instalação dos experimentos, as áreas foram cultivadas com preparo convencional (PC) durante 25 anos, porém com culturas eadubações diferentes. O experimento I, instalado em 1993, foi realizado no sistema de preparo reduzido (PR), com abertura de sulcos para semeadura do milho com arado estreito $(0,1 \mathrm{~m})$ de fabricação artesanal. O experimento II, instalado em 1994, foi realizado no sistema de PC, com uma aração e duas gradagens. As parcelas no PR foram de $5 \times 24$ m e no PC $6 \times 24 \mathrm{~m}$. O delineamento experimental foi de blocos ao acaso com três repetições.

Cada experimento consistiu de cinco sistemas de cultura: milho + guandu anão (Cajanus cajan, L. cv. roxo anão); milho + mucuna cinza (Stilozobium niveum, Kuntze); milho +feijão-de-porco (Canavalia ensiformis, L.); milho +soja preta (Glicinesp) e milho isolado. Duranteo inverno, as áreas permaneceram em repouso. O manejo do solo iniciou em junho, após a ocorrência das primeiras geadas, com o manejo mecânico dos resíduos do cultivo anterior por meio de um rolo-faca com tração animal. Em agosto, foi realizada a dessecação no sistema PR e, em setembro, a aração e gradagem no PC. A adubação de manutenção com N, P e K foi feita a Ianço, com uréia, superfosfato triplo e cloreto de potássio nas doses recomendadas pela CFS-RS/SC (1995) para expectativa de rendimento de 3 a 6 t ha-1 de milho.

A semeadura do milho, cultivar Cargil 701, foi realizada na primeira quinzena de outubro, com espaçamento de 1,0 m entre linhas e população de 50.000 plantas ha-1. As plantas de cobertura intercalares, com uma linha de leguminosa por entre linha de milho, nas densidades recomendadas para cada espécie (Monegat, 1996), foram semeadas 15 dias após a emergência do milho, com exceção da mucuna cinza, semeada 45 dias após a emergência do milho, dado seu rápido desenvolvimento inicial e hábito de crescimento trepador. As ervas espontâneas foram controladas com capinas manuais. As plantas de milho foram dobradas no estádio de maturação fisiológica para favorecer a entrada deluz e o desenvolvimento das leguminosas.

Em junho de 1999, foram col etadas amostras de solo, na entrelinha da cultura do milho e na mata nativa, nas profundidade de 0-0,05 e 0,05-0,1 m. Foram determinados os teores de $\mathrm{CO}, \mathrm{Ca}, \mathrm{Mg}, \mathrm{K}$ e Al trocáveis, pH em água e em $\mathrm{KCl}$ (Tedesco et al., 1995) e calculado o delta $\mathrm{pH}(\Delta \mathrm{pH})$ (Mekaru \& Uehara, 1972). Determinou-se o ponto de efeito salino nulo (PESN), por meio de titulação potenciométrica (E mbrapa, 1997), em amostras compostas pelas três repetições, da mata nativa e nos preparos do solo, nos sistemas de mai or aporte, milho mais mucuna cinza, e de menor aporte, milho isolado. Os teores de argila, silte e areia na TFSA foram determinadas pel o método da pi peta, usandoseágua e $\mathrm{NaOH}$ como dispersantes (Gee \& Bauder, 1986) e o grau de floculação da argila foi calculado.

A análise mineralógica foi realizada para a profundidade de 0-0,1 m seguindo o preparo das amostras o método descrito por Whittig \& Allardice (1986). Foram separadas as frações areia (53$2.000 \mu \mathrm{m})$, silte $(2-53 \mu \mathrm{m})$ eargila $(<2 \mu \mathrm{m})$, sendoa argila saturada por $\mathrm{K}, \mathrm{Mg}$ e $\mathrm{Mg}$ mais glicerol à temperatura ambiente. A análise por difratometria deraios X (DRX) foi feita em lâminas da fração argila orientada e no pó das frações silte e areia. Foi utilizado um equipamento Philips, com radiação de $\mathrm{Cu}-\mathrm{K} \alpha$ e monocromador de grafite (Kunze \& Dixon, 1986). As lâminas de argila saturadas com K, após serem analisadas, foram aquecidas na mufla a 100, 350 e $500{ }^{\circ} \mathrm{C}$, obtendo-se os difratogramas após cada aquecimento.

Na fração areia, predominou quartzo, com presença de ilmenita e hematita. Na fração silte, além dos mineirais presentes na areia, observou-se pequena quantidade de goethita e magnetita/ maghemita. Na fração argila, predominou caulinita e, em menor teor, mineral 2:1 com polímeros de Al nas entrecamadas, hematita e goethita.

Para determinar a estabilidade dos agregados, amostras de solo, após serem destorroadas e tamisadas, para obter a classe de agregados entre 4,76 e 8,35 mm, foram agitadas em água, com três repetições de laboratório, utilizando peneiras com malhas de 4,76, 2,0, 1,0 e 0,21 mm, bem como calculado seu diâmetro médio ponderado (DMP), pelo método de Kemper \& Chepil (1965).

A análise estatística consistiu da análise da variância, para o model o experimental de blocos ao 
acaso com parcelas subdivididas, com culturas nas parcelas princi pais e profundidades nas subparcelas. A comparação entre médias de tratamentos foi avaliada pel oteste deDuncan a $5 \%$. A relação entre as variáveis foi testada pela significância dos coeficientes de regressões lineares (SAS, 1990).

\section{RESULTADOS E DISCUSSÃO}

\section{Carbono orgânico do solo}

O CO foi influenciado pelos fatores: cultura e profundidade, no preparo reduzido, e cultura, no preparo convencional (Quadro 2). O teor de CO do solo na média das duas profundidades na mata nativa foi $18 \%$ superior ao da média dos sistemas decultura do PR e $21 \%$ superior ao do PC (Figura 1 ), provavelmente pelo grande aporte de resíduos orgânicos, não-revolvimento do solo e reduzida erosão hídrica na mata nativa.

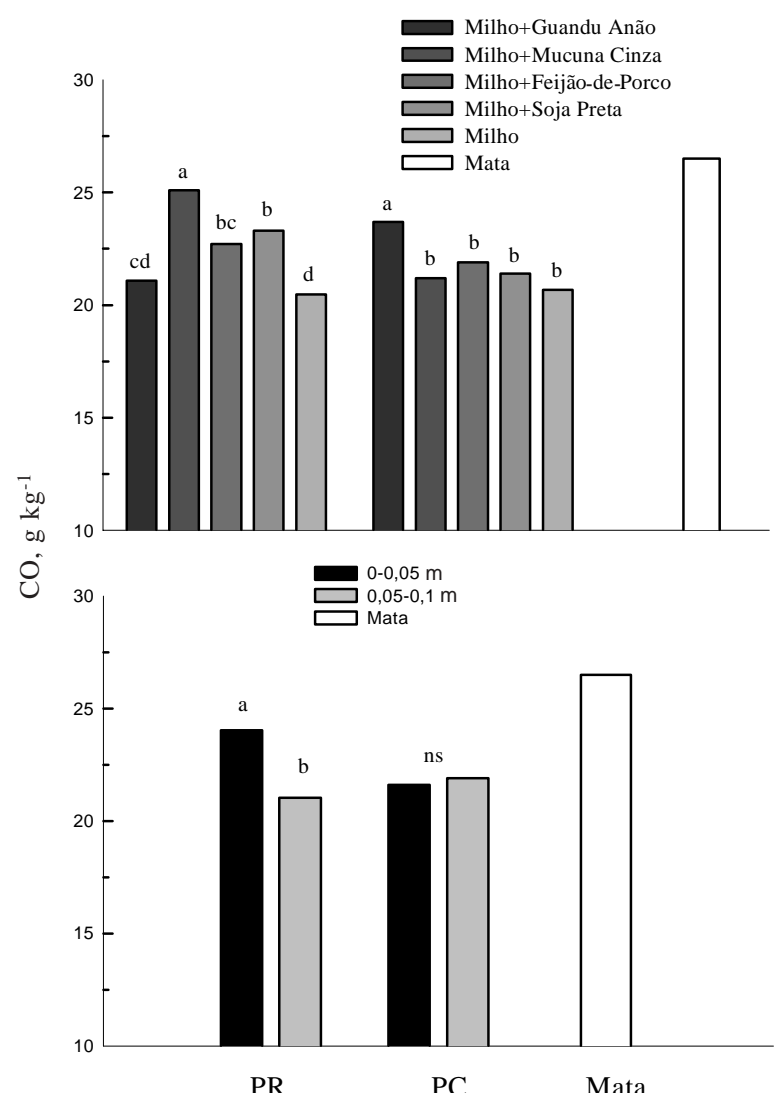

Figura 1. Teor médio de carbono orgânico do solo (CO) na camada de 0-0,1 $\mathrm{m}$ de profundidade nos sistemas de cultura com preparo reduzido (PR) e convencional (PC) e na mata nativa. Para comparar as profundidades (0-0,05 e 0,05$0,1 \mathrm{~m})$, foi calculada a média dos cinco sistemas de culturas em cada sistema de preparo. Letras minúsculas diferentes indicam diferença significativa (Duncan a $5 \%$ ).
Foi observado acúmulo de CO na camada de 0$0,05 \mathrm{~m}$ do solo em PR e não no PC (Figura 1 ), visto que, naquelesistema, orevolvimento ea conseqüente incorporação ao solo dos resíduos ocorrem apenas na linha de semeadura, enquanto no PC toda a camada de solo foi revolvida nas operações de preparo, incorporando os resíduos vegetais e acel erando sua decomposição. No PR, o sistema com mucuna cinza apresentou o maior teor de CO (Figura 1), seguido pelos sistemas feijão-de-porco e soja preta, enquanto, no sistema milho sem planta de cobertura, oteor de CO foi menor. No PC, apenas o sistema com guandu anão aumentou oteor de CO. Neste mesmo experimento, Spagnol lo et al. (2002) observaram que o aporte de massa seca foi, respectivamente, para os sistemas de PR e PC, de 5,48 e 5,01 t ha-1, para o guandu anão; 4,99 e 4,29, para mucuna cinza; 1,51 e 2,83, para o feijão-deporco, e 1,35 e 1,26 t ha-1, para a soja preta. Portanto, as diferenças observadas nos teores de CO estão também relacionadas com os aportes de cada sistema de cultura, conforme observado por Bayer \& Mielniczuk (1997) em Argissolo Vermelho.

Somadas as diferenças no aporte de matéria orgânica, Bayer et al. (2000) observaram em um Argissolo Vermel ho que o preparo convencional apresentou taxa de perda anual de matéria orgânica de $0,054 \mathrm{ano}^{-1}$, enquanto, no preparo reduzido, foi de $0,039 \mathrm{ano}^{-1}$, ou seja, uma redução na perda de matéria orgânica da ordem de $28 \%$ no preparo reduzido. Os autores ressaltaram que estas taxas são dependentes da textura e mineralogia do solo, condições climáticas e da intensidade do processo erosivo. Portanto, ao longo do tempo, o acúmulo de matéria orgânica no PR comparado ao PC será maior, refletindo, assim, em outros atributos do solo.

\section{Cátions trocáveis, acidez ativa e ponto de efeito salino nulo (PESN) do solo}

As características quími cas foram distintas entre os sistemas PR ePC, principalmente com relação ao $\mathrm{pH}$ (Quadro 1), com valores médios de pH em água de 5,6 em PR e 6,5 em PC e do $\mathrm{pH}$ em $\mathrm{KCl}$ de 4,3 em PR e 5,1 em PC. O sistema em PR apresentou uma unidade menor de $\mathrm{pH}$ do que no PC, o que reflete o diferente histórico de adubações e correções da acidez nas áreas experimentais. No PC, o pH do solo refletiu os teores mais el evados de $\mathrm{Ca}$ e $\mathrm{Mg}$ trocáveis, soma de bases, capacidade detroca efetiva de cátions e menor Al trocável (Quadro 1).

Na mata, oPESN foi de 4,0 e, apesar deo manejo alterar o teor de CO (Figura 1), o PESN não foi alterado pelos sistemas de preparo ou de culturas com maior aporte de resíduos no sistema mil ho mais mucuna cinza, ou menor no mil ho isolado. Os valores de PESN foram semelhantes aos verificados por Albuquerque et al. (2000), num Latossolo Bruno alumínico de Santa Catarina $(3,8)$, e dentro dos 
Quadro 1. Teores de Ca, Mg, Al e K trocáveis, CTC efetiva, soma de bases (SB), pH em água, pH em KCl, ponto de efeito salino nulo (PESN) e $\Delta \mathrm{pH}$ na camada de 0-0,1 m do Latossolo Vermelho distroférrico, nos sistemas de cultura ${ }^{(1)}$ com preparo reduzido, convencional e na mata nativa

\begin{tabular}{|c|c|c|c|c|c|c|c|c|c|c|}
\hline Sistema de cultura & $\mathrm{Ca}^{2+}$ & $\mathbf{M g}^{2+}$ & $\mathbf{A l}^{3+}$ & $\mathbf{K}^{+}$ & CTC & SB & pH $\mathrm{H}_{2} \mathrm{O}$ & pH $\mathrm{kCl}$ & PESN & $\Delta \mathbf{p H}$ \\
\hline & \multicolumn{10}{|c|}{$\mathrm{cmol}_{\mathrm{c} \mathrm{kg}} \mathrm{K}^{-1}$} \\
\hline & \multicolumn{10}{|c|}{ Preparo reduzido } \\
\hline Milho + guandu anão & 4,4 & 2,3 & 0,5 & 0,82 & 8,0 & 7,5 & 5,3 & 4,2 & nd & $-1,1$ \\
\hline Milho + mucuna cinza & 5,2 & 2,7 & 0,4 & 0,90 & 9,2 & 8,8 & 5,5 & 4,3 & 4,0 & $-1,2$ \\
\hline Milho + feijão-de-porco & 4,9 & 2,7 & 0,4 & 0,77 & 8,8 & 8,4 & 5,6 & 4,3 & nd & $-1,3$ \\
\hline Milho + soja preta & 5,3 & 3,1 & 0,3 & 0,73 & 9,4 & 9,1 & 5,8 & 4,4 & nd & $-1,4$ \\
\hline Milho & 4,7 & 2,6 & 0,4 & 0,68 & 8,4 & 8,0 & 5,7 & 4,3 & 4,1 & $-1,4$ \\
\hline \multirow[t]{2}{*}{ Média } & 4,9 & 2,7 & 0,4 & 0,78 & 8,8 & 8,4 & 5,6 & 4,3 & 4,05 & $-1,3$ \\
\hline & \multicolumn{10}{|c|}{ Preparo convencional } \\
\hline Milho + guandu anão & 6,2 & 4,8 & 0,2 & 0,75 & 11,9 & 11,7 & 6,2 & 5,0 & nd & $-1,2$ \\
\hline Milho + mucuna cinza & 6,9 & 5,6 & 0,2 & 0,72 & 13,4 & 13,2 & 6,5 & 5,1 & 4,0 & $-1,4$ \\
\hline Milho + feijão-de-porco & 6,5 & 5,2 & 0,1 & 0,81 & 12,7 & 12,5 & 6,6 & 5,1 & nd & $-1,5$ \\
\hline Milho + soja preta & 6,3 & 5,3 & 0,1 & 0,61 & 12,3 & 12,2 & 6,7 & 5,1 & nd & $-1,6$ \\
\hline Milho & 5,7 & 5,0 & 0,1 & 0,71 & 11,5 & 11,4 & 6,7 & 5,1 & 4,0 & $-1,6$ \\
\hline \multirow[t]{3}{*}{ Média } & 6,3 & 5,2 & 0,2 & 0,72 & 12,4 & 12,2 & 6,5 & 5,1 & 4,0 & $-1,4$ \\
\hline & \multicolumn{10}{|c|}{ Mata nativa } \\
\hline & 3,8 & 2,5 & 1,0 & 0,2 & 7,5 & 6,5 & 5,3 & 4,1 & 4,0 & $-1,2$ \\
\hline
\end{tabular}

(1) Os sistemas de cultura são compostos de milho + guandu anão, milho + mucuna cinza, milho +feijão-de-porco, milho + soja preta, milho isolado. nd = não determinado.

limites citados por Magalhães \& Page (1984), em Latossolos do Brasil Central (entre 3,6 e 4,6). Os valores negativos de delta $\mathrm{pH}$ (Quadro 1) indicam que o sol o apresenta carga líquida negativa em todos os sistemas de uso e manejo. Geralmente, quanto maior for a diferença entre o PESN e o pH do solo, maior a tendência de prevalecerem as forças de repulsão sobre as de aproximação das partículas, resultando em menor grau de floculação.

\section{Grau de floculação}

O grau de floculação foi influenciado pela cultura intercalar e profundidade em ambos os experimentos (Quadro 2). Na média das duas profundidades, o grau de floculação (GF) da argila no solo sob mata nativa $\left(585 \mathrm{~g} \mathrm{~kg}^{-1}\right)$ foi semel hante ao da média do PR (600 $\left.\mathrm{g} \mathrm{kg}^{-1}\right)$ e 7,3 \% superior ao da média do PC (547 $\left.\mathrm{g} \mathrm{kg}^{-1}\right)$ (Figura 2). I sso pode ser resultante da semel hança do ponto de efeito salino nulo (PESN) entre a mata e o PR e, ao maior $\mathrm{pH}$ e conseqüentemente, delta pH no PC (Quadro 1), o que aumenta a repulsão e favorece a dispersão das partículas. Em sol os de carga variável ecom baixo PESN, como o solo em questão, com a el evação do $\mathrm{pH}$, aumentam a carga líquida negativa e a espessura da dupla camada difusa, favorecendo a dispersão da argila, conforme constatado também por Albuquerque et al. (2000) em um Latossolo Bruno. Segundo Morelli \& Ferreira (1987), esta maior dispersão pode ser amenizada pelos efeitos benéficos ao sistema, proporcionados pela redução do Al tóxico às plantas com conseqüente aumento no aporte de resíduos orgânicos.

Em ambos os sistemas de preparo, a introdução das plantas de cobertura alterou o teor de $\mathrm{CO}$ do solo (Figura 1), mas não o grau de floculação da argila, quando comparado ao sistema com milho isolado (Figura 2). Observando os dois experimentos, o comportamento das culturas não seguiu o mesmo padrão, ou seja, enquanto no PR o maior grau de floculação foi observado no sistema mil ho mais feijãode-porco, no PC foi observado no sistema milho mais soja preta.

No PR e PC, observou-se maior GF na camada de 0-0,05 m, comparada com a de 0,05 a 0,1 m, provavelmente pela ação conjunta da matéria orgânica, atividade mi crobiana, sistema radicular e concentração de cátions trocáveis, bem como pela ação dos cicl os de umedecimento e secagem. Kemper et al. (1987) afirmaram que, com a secagem, os íons e colóides migram de locais de maior energia para locais de menor energia da solução, aumentando a força de ligação entre partículas.

\section{Estabilidade de agregados do solo}

Após cinco anos de utilização do PR, a estabilidade de agregados $(3,09 \mathrm{~mm})$ foi semelhante à do PC $(3,34 \mathrm{~mm})$, diferente do esperado aumento quando seutilizaram sistemas conservacionistas de preparo. 
Quadro 2. Probabilidade de o valor $t$ tabulado $\left(t_{n-1} ; \alpha=0,05\right)$ ser maior do que $t$ calculado para aceitar a hipótese nula (Ho:u $=u_{0}$ ), para as causas da variação: bloco; cultura, profundidade e interação cultura x profundidade para as propriedades físicas do Latossolo Vermelho sob preparo reduzido (PR) e convencional (PC)

\begin{tabular}{llllllll}
\hline \multirow{2}{*}{ Causa de variação } & \multicolumn{3}{c}{ PR } & & \multicolumn{3}{c}{ PC } \\
\cline { 2 - 3 } & CO(1) & GF & DMP & & CO & GF & DMP \\
\hline Bloco & 0,03 & 0,03 & 0,24 & & 0,72 & 0,02 & 0,45 \\
Cultura & 0,01 & 0,05 & 0,60 & & 0,01 & 0,05 & 0,15 \\
Profundidade & 0,01 & 0,01 & 0,61 & & 0,48 & 0,01 & 0,01 \\
Cultura * Profundidade & 0,37 & 0,55 & 0,89 & & 0,67 & 0,71 & 0,74 \\
CV (\%) & 6,5 & 3,7 & 20,1 & & 5,0 & 3,6 & 12,7 \\
\hline
\end{tabular}

(1) CO = carbono orgânico; GF = grau de floculação e DMP = diâmetro médio ponderado.

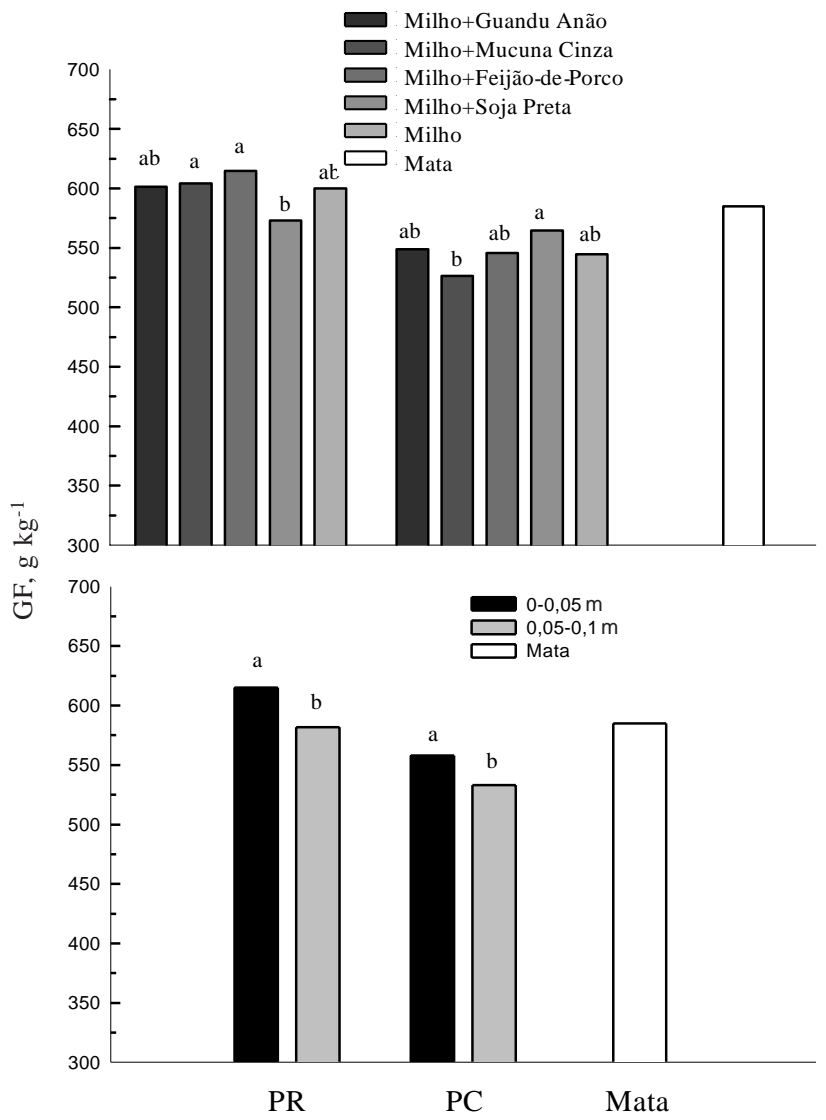

Figura 2. Valor médio do grau de floculação (GF), na camada de 0-0,1 m, nos sistemas de cultura com preparo reduzido (PR) e convencional (PC) ena mata nativa. Para comparar as profundidades (0-0,05 e 0,05-0,1 m), foi calculada a média dos cinco sistemas de culturas em cada sistema de preparo. Letras minúsculas diferentes indicam diferença significativa (Duncan a $5 \%$ ).

Também não foi alterada pelas culturas utilizadas intercalares ao milho. No PR, oDMP foi semel hante entre as culturas, variando de $2,87 \mathrm{~mm}$, no sistema com feijão-de-porco, a $3,37 \mathrm{~mm}$, no sistema com guandu anão e no PC variou de $3,10 \mathrm{~mm}$, no sistema com mucuna cinza, a 3,64 mm, no sistema com guandu anão.

Houve maior estabilidade de agregados na camada de 0,05-0,1 m comparada à camada de 0$0,05 \mathrm{~m}$ no PC, o que, segundo Carpenedo \& Mielniczuk (1990), pode estar relacionado com a maior coesão dos macroagregados proporcionada pela aproximação das partículas em operações de preparo, considerados agregados de menor qualidade, ou pelo efeito negativo de ciclos intensos de secagem e umedecimento, enfraquecendo as ligações entre partículas na camada de $0-0,05 \mathrm{~cm}$. É importante ressaltar que o grau de floculação no PC foi maior na camada de 0-0,05 m. Portanto, os processos envolvidos na floculação de partículas e na estabilização de macroagregados podem ser diferentes, ou seja, o que beneficia o GF pode não beneficiar a estabilidade de agregados.

$\mathrm{Na}$ camada de 0-0,1 m, a estabilidade de agregados no sol o sob mata nativa foi alta $(4,24 \mathrm{~mm})$, não tendo o PR $(3,09 \mathrm{~mm})$ recuperado esta propriedade do solo que havia sido degradada pelo PC (3,34 mm) em relação à mata (Figura 3). A nãorecuperação da estabilidade dos agregados no sistema PR no presente estudo pode estar relacionada com o curto período de utilização dos diferentes sistemas de manejo e com a alta estabilidade estrutural deste solo, que, além de argiloso, apresenta minerais com cargas negativas permanentes e dependentes do $\mathrm{pH}$, de matéria orgânica com cargas negativas dependentes do pH e deóxidos deFecom predomínio de cargas positivas dependentes do pH. Nessas condi ções, as alterações na estabilidade dos agregados foram de pequena magnitude, ao contrário do que foi observadoem solos arenosos e com baixo teor de óxidos (Albuquerque et al., 1996). Verificou-se que, na mata e no campo nativo, atuam, com maior intensidade, moléculas orgânicas transitórias, hifas de fungos, mucilagens e raízes (Tisdall \& Oades, 1982), importantes agentes relacionados com a gênese dos agregados. 


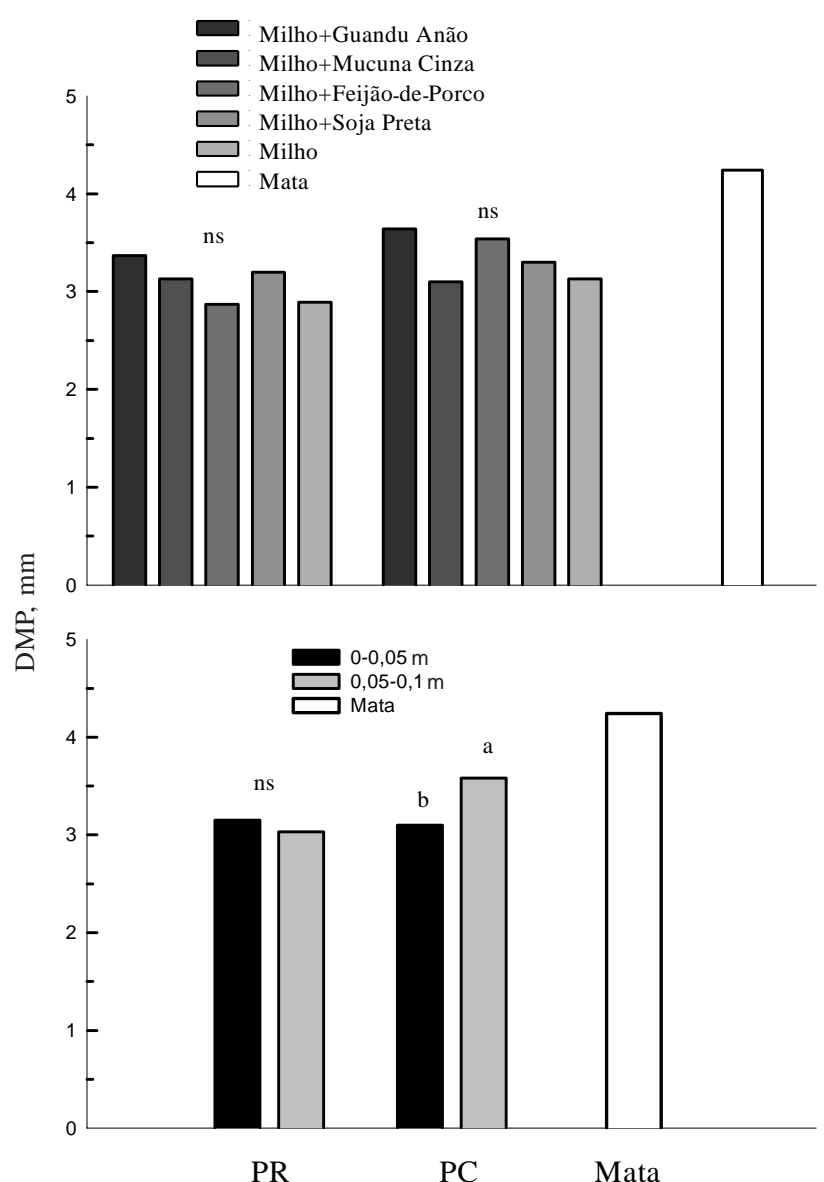

Figura 3. Diâmetro médio ponderado (DMP) de agregados do solo, na camada de 0-0,1 m de profundidade, nos sistemas de cultura com preparo reduzido (PR) e convencional (PC) e na mata nativa. Para comparar as profundidades $(0-0,05$ e $0,05-0,1 \mathrm{~m})$, foi calculada a média dos cinco sistemas de culturas em cada sistema de preparo. Letras minúsculas diferentes indicam diferença significativa (Duncan a $5 \%$ ).

De modo geral, a estabilidade de agregados em sistemas conservacionistas mostrou-se mai or do que no preparo convencional. Em Latossolo Vermelho distrófico textura argilosa, Campos et al. (1995) observaram um aumento do DMG de $1,2 \mathrm{~mm}$, em PC, para 2,0 mm após sete anos de uso do sistema plantio direto. Por sua vez, Silva et al. (1998) em Goiás, num Latossolo Vermelho distrófico textura argilosa, verificaram uma variação no DMG dos agregados de 1,4 mm em PC com guandu a 4,4 mm em sol o sob cerrado nativo. Castro Filho et al . (1998), num Latossol o Vermel ho distroférrico em Londrina (PR), comparando diferentes sistemas de rotação de culturas em plantio direto e preparo convencional, num experimento com 14 anos de duração, observaram maior estabilidade dos agregados, quando foi utilizado plantio direto e nas sucessões de culturas que incluíram espécies com relação $\mathrm{C} / \mathrm{N}$ mais alta (milho). Costa et al. (2003) em Latossolo Bruno em Guarapuava (PR), observaram aumento do DMG na camada de $0-0,05$ m de 1,6 no PC para 3,7 mm no PD após 21 anos de instalação do experimento.

Comparando a vegetação nativa de Cerrado com o uso do solo no sistema plantio direto e preparo convencional em um Latossolo Vermelho, Mendes et al. (2003) observaram maior estabilidade de agregados no Cerrado do que no PD, sendo o PC o sistema com menor estabilidade de agregados. Observaram que o teor de matéria orgânica e do C prontamente mineralizável nos macroagregados foi maior do que nos microagregados nos sistemas Cerrado ePD, enquanto no PC nãohouve diferenças. I sto comprova que no PC ocorre a oxidação da matéria orgânica, principal mentedos macroagregados com redução de sua estabilidade.

Quando anal isados todos os dados conjuntamente, foram observadas correlações entre o CO com o DMP dos agregados $(r=0,43 ; p<0,01$ ) (Quadro 3), pelo fato de a matéria orgânica atuar como um agente de agregação temporário, principalmente de macroagregados (Tisdall \& Oades, 1982). Carpenedo \& Mielniczuk (1990) também encontraram correlação positiva entre DMP e matéria orgânica em um Latossolo Vermel ho distroférrico argiloso $(r=0,80)$ e num $L$ atossolo Vermel ho alumi noférrico argiloso $(r=0,69)$ e Campos et al. (1995) num Latossolo Vermelho distrófico $(r=0,85)$ após sete anos comparando sistemas de preparo do solo.

Neste estudo, a obtenção do coeficiente de correlação baixo, comparativamente à literatura, pode indicar a existência de outros fatores inerentes aos sistemas de culturas ou ao solo, atuando sobrea agregação.

O pH em água não apresentou correlação com o DMP (Quadro 3); entretanto, apresentou correlação negativa com o GF $(r=-0,64 ; p<0,01)$. Com a el evação do pH aumentaram os teores de Ca e Mg trocáveis, a CTC efetiva e a soma de bases, os quais também apresentaram correl açãonegativa com o GF $(r=-0,60$ para $\mathrm{Ca}$ e $r=-0,66$ para $\mathrm{Mg} ; \mathrm{p}<0,01)$. Provavel mente, o que determinou a correlação foi o aumento do $\mathrm{pH}$, relacionado com o aumento das cargas negativas com conseqüente repulsão entre partículas e dispersão de argila. Por outro lado, o Al trocável apresentou correlação positiva e significativa com o GF ( $r=0,46 ; p<0,01)$ e com o $\operatorname{DMP}(r=0,31, p<0,01)$, provavel menteem virtude da formação de pontes de cátions entreas partículas minerais e orgânicas, elevando a estabilidade de agregados e reduzindo a dispersão da argila. Estas constatações também foram observadas por Albuquerque et al. (2000) em um Latossolo Bruno submetido a doses crescentes de cal cário.

Em magnitude variável com o tipo de solo e condições climáticas, sistemas de manejo que adicionam grandes quantidades de resíduos vegetais 
Quadro 3. Coeficientes de correlação ( $r$ ) e probabilidade ( $p$ ) entre atributos químicos e físicos do Latossolo Vermelho sob sistema de preparo reduzido e preparo convencional

\begin{tabular}{|c|c|c|c|c|c|c|c|c|c|c|c|}
\hline & & GF & pH нго & $\Delta \mathbf{p H}$ & DMP & $\mathrm{Ca}$ & Mg & Al & K & CTC ef & SB \\
\hline $\mathrm{CO}^{(1)}$ & $\begin{array}{l}r \\
p\end{array}$ & $\begin{array}{l}0,14 \\
0,26\end{array}$ & $\begin{array}{r}-0,41 \\
0,01\end{array}$ & $\begin{array}{r}-0,45 \\
0,01\end{array}$ & $\begin{array}{l}0,43 \\
0,01\end{array}$ & $\begin{array}{r}-0,19 \\
0,14\end{array}$ & $\begin{array}{r}-0,28 \\
0,02\end{array}$ & $\begin{array}{l}0,33 \\
0,01\end{array}$ & $\begin{array}{r}-0,03 \\
0,78\end{array}$ & $\begin{array}{r}-0,22 \\
0,08\end{array}$ & $\begin{array}{r}-0,24 \\
0,05\end{array}$ \\
\hline GF & $\begin{array}{l}r \\
p\end{array}$ & & $\begin{array}{r}-0,64 \\
0,01\end{array}$ & $\begin{array}{r}-0,37 \\
0,01\end{array}$ & $\begin{array}{r}-0,20 \\
0,11\end{array}$ & $\begin{array}{r}-0,60 \\
0,01\end{array}$ & $\begin{array}{r}-0,66 \\
0,01\end{array}$ & $\begin{array}{l}0,46 \\
0,01\end{array}$ & $\begin{array}{l}0,08 \\
0,54\end{array}$ & $\begin{array}{r}-0,63 \\
0,01\end{array}$ & $\begin{array}{r}-0,63 \\
0,01\end{array}$ \\
\hline $\mathrm{pH} \mathrm{H}_{2} \mathrm{O}$ & $\begin{array}{l}r \\
p\end{array}$ & & & $\begin{array}{l}0,69 \\
0,01\end{array}$ & $\begin{array}{r}-0,10 \\
0,42\end{array}$ & $\begin{array}{l}0,82 \\
0,01\end{array}$ & $\begin{array}{l}0,94 \\
0,01\end{array}$ & $\begin{array}{r}-0,70 \\
0,01\end{array}$ & $\begin{array}{l}0,11 \\
0,37\end{array}$ & $\begin{array}{l}0,89 \\
0,01\end{array}$ & $\begin{array}{l}0,89 \\
0,01\end{array}$ \\
\hline$\Delta \mathrm{pH}$ & $\begin{array}{l}r \\
p\end{array}$ & & & & $\begin{array}{r}-0,10 \\
0,43\end{array}$ & $\begin{array}{l}0,37 \\
0,01\end{array}$ & $\begin{array}{l}0,49 \\
0,01\end{array}$ & $\begin{array}{r}-0,34 \\
0,01\end{array}$ & $\begin{array}{r}-0,22 \\
0,08\end{array}$ & $\begin{array}{l}0,41 \\
0,01\end{array}$ & $\begin{array}{l}0,42 \\
0,01\end{array}$ \\
\hline DMP & $\begin{array}{l}r \\
p\end{array}$ & & & & & $\begin{array}{r}-0,15 \\
0,23\end{array}$ & $\begin{array}{r}-0,03 \\
0,78\end{array}$ & $\begin{array}{l}0,31 \\
0,01\end{array}$ & $\begin{array}{r}-0,35 \\
0,01\end{array}$ & $\begin{array}{r}-0,09 \\
0,49\end{array}$ & $\begin{array}{r}-0,12 \\
0,34\end{array}$ \\
\hline $\mathrm{Ca}$ & $\begin{array}{l}r \\
p\end{array}$ & & & & & & $\begin{array}{l}0,89 \\
0,01\end{array}$ & $\begin{array}{r}-0,81 \\
0,01\end{array}$ & $\begin{array}{l}0,40 \\
0,01\end{array}$ & $\begin{array}{l}0,97 \\
0,01\end{array}$ & $\begin{array}{l}0,98 \\
0,01\end{array}$ \\
\hline $\mathrm{Mg}$ & $\begin{array}{l}r \\
p\end{array}$ & & & & & & & $\begin{array}{r}-0,66 \\
0,01\end{array}$ & $\begin{array}{l}0,13 \\
0,29\end{array}$ & $\begin{array}{l}0,97 \\
0,01\end{array}$ & $\begin{array}{l}0,96 \\
0,01\end{array}$ \\
\hline Al & $\begin{array}{l}r \\
p\end{array}$ & & & & & & & & $\begin{array}{r}-0,49 \\
0,01\end{array}$ & $\begin{array}{r}-0,71 \\
0,01\end{array}$ & $\begin{array}{r}-0,77 \\
0,01\end{array}$ \\
\hline K & $\begin{array}{l}r \\
p\end{array}$ & & & & & & & & & $\begin{array}{l}0,32 \\
0,01\end{array}$ & $\begin{array}{l}0,35 \\
0,01\end{array}$ \\
\hline CTC ef & $\begin{array}{l}r \\
p\end{array}$ & & & & & & & & & & $\begin{array}{l}0,99 \\
0,01\end{array}$ \\
\hline
\end{tabular}

(1) $\mathrm{CO}=$ carbono orgânico; GF = grau de floculação; $\mathrm{pH}_{\mathrm{H} 2 \mathrm{O}}=\mathrm{pH}$ em água; $\Delta \mathrm{pH}=$ Delta $\mathrm{pH}$; DMP = diâmetro médio ponderado; Ca, Mg, Al e K trocáveis; CTC ef =CTC efetiva e; SB = soma de bases.

ao solo e determinam uma baixa intensidade de revolvimento aumentam o teor de CO, a CTC e a estabilidade de agregados (Tisdall \& Oades, 1982; Paladini \& Mielniczuk, 1991; Campos et al., 1995; Debarba \& Amado, 1997; Costa et al., 2003), sendo importante para aumentar a resistência do solo à erosão e recuperar sua qualidade física, química e bi ológica, proporcionando condições necessárias para obtenção de adequada produtividade dos cultivos. Por outro lado, o revolvimento do solo expõe a matéria orgânica que estava protegida no interior dos agregados, favorecendo sua oxidação com conseqüente redução do seu teor, da CTC e da estabilidade de agregados. Geralmente, o sistema demanejo do sol o que mais degrada as características físicas é o preparo convencional e o que menos degrada é o plantio direto, enquanto o preparo reduzido apresenta comportamento intermediário, conforme constatado por Costa (2001), em Latossolo Bruno do Paraná, e por Lima et al. (2003), em um Planossolo do Rio Grande do Sul.

\section{CONCLUSÕES}

1. O uso do solo degradou suas propriedades físicas, comparativamente ao sistema com mata nativa.
2. As plantas de cobertura de verão aumentaram o teor de CO, mas não modificaram a estabilidade dos agregados e o grau de floculação. Em períodos mais longos, as plantas de cobertura, associadas aos preparos conservacionistas, pelo aumento do CO, podem melhorar as características físicas do solo.

\section{AGRADECIMENTOS}

Os autores agradecem a Capes e ao CNPq, pela concessão de bolsas de estudo, e à EPAGRI e UDESC, pelo apoio institucional para a realização deste estudo.

\section{LITE RATURA CITADA}

ALBUQUERQUE, J.A.; REINERT, D.J .; FIORIN, J .E.; RUEDELL, J .; PETRERE, C. \& FONTINELLI, F. Rotação de culturas e sistemas de manejo do solo: efeito sobre a forma da estrutura do solo ao final de sete anos. R. Bras. Ci. Solo, 19:115-119, 1995.

ALBUQUERQUE, J.A; REINERT, D.J. \& FIORIN, J.E. Variabilidade de solo e planta em Podzólico VermelhoAmarelo. R. Bras. Ci. Solo, 20:151-157, 1996. 
ALBUQUERQUE, J.A.; BAYER, C.; ERNANI, P.R. \& FONTANA, E.C. Propriedades físicas e el etroquímicas de um Latossolo Bruno afetadas pela calagem. R. Bras. Ci. Solo, 24:295-300, 2000.

ALBUQUERQUE, J .A.; SANGOI, L. \& ENDER, M. Efeitos da integraçãolavoura-pecuária nas propriedades físicas do solo e características da cultura do milho. R. Bras. Ci. Solo, 25:717-723, 2001.

ALVARENGA, R.C.; FERNANDES, B.; SILVA, T.C.A. \& RESENDE, M. Estabilidade de agregados de um $L$ atossolo Roxo sob diferentes métodos de preparo do solo e de manejo da palhada de milho. R. Bras. Ci. Solo, 10:273-277, 1986.

AMADO, T.J .C. \& MIELNICZUK, J . Estimativa da adubação nitrogenada para o milho em sistemas de manejo eculturas de cobertura do solo. R. Bras. Ci. Solo, 24:553-560, 2000.

ARGENTON, J. Propriedades físicas do solo em dois sistemas de cultivo com plantas de cobertura de verão intercalares à cultura do milho. Lages, Universidade do Estado de Santa Catarina, 2000. 97p. (Tese de Mestrado)

BAYER, C. \& MIELNICZUK, J. Características químicas do sol o afetadas por métodos de preparo esistemas de cultura. R. Bras. Ci. Solo, 21:105-112, 1997.

BAYER, C.; MIELNICZUK, J \& \& MARTIN NETO, L. Efeito de sistemas de preparo e de cultura na dinâmica da matéria orgânica e na mitigação das emissões de $\mathrm{CO}_{2}$. R. Bras. Ci. Solo, 24:599-607, 2000.

BORGES, D.F.; REINERT, D.J .; CAMPOS, B.C.; FUCKS, L.F.M.; NICOLODI, R. \& BOENI, M. Recuperação da agregação pelo uso de leguminosas e gramíneas em solos Podzólicos Vermelho-Amarelo. In: REUNIÃO BRASILEIRA DE MANEJ O E CONSERVAÇÃO DO SOLO E DA ÁGUA, 10., Florianópolis, 1994. Resumos. Florianópolis, SociedadeBrasileira de Ciência doSolo, 1994. p.428.

CAMPOS, B.C.; REINERT, D.J .; NICOLODI, R.; RUEDELL, J . $\&$ PETRERE, C. Estabilidade estrutural de um Latossolo Vermelho-Escuro distrófico após sete anos de rotação de culturas e sistemas de manejo do solo. R. Bras. Ci. Solo, 19:121-126,1995.

CARPENEDO, V. \& MIELNICZUK, J. Estado de agregação e qualidade de agregados de Latossol os Roxos, submetidos a diferentes sistemas de manejo. R. Bras. Ci. Solo, 14:99105, 1990.

CASTRO FILHO, C.; MUZILLI, O. \& PODANOSCHI, A.L. Estabilidade dos agregados e sua relação com o teor de carbono orgânico num Latossolo Roxo distrófico, em função de sistemas de plantio, rotação de culturas e métodos de preparo das amostras. R. Bras. Ci. Solo, 22:527-538, 1998.

COMISSÃO DE FERTILIDADE DO SOLO - CFS-RS/SC. Recomendação de adubação e calagem para o estado do Rio Grande do Sul e Santa Catarina. 3ed. Passo Fundo, Sociedade Brasileira de Ciência do Solo - Núcleo Regional/ Embrapa-CNPT, 1995. 128p.

COSTA, F.S. Propriedades físicas e produtividade de culturas de um Latossolo Bruno sob sistemas de manejo em experimento de longa duração. Lages, Universidade do Estado de Santa Catarina, 2001. 98p. (Tese de Mestrado)
COSTA, F.S.; ALBUQUERQUE, J .A.; BAYER, C.; FONTOURA, S.M.V. \& WOBETO, C. Propriedades físicas de um Latossolo Bruno afetadas pelos sistemas de plantio direto e preparo convencional. R. Bras. Ci. Solo, 27:527-535, 2003.

DEBARBA, L. \& AMADO, T.J.C. Desenvolvimento de sistemas de produção de milho no sul do Brasil com características de sustentabilidade. R. Bras. Ci. Solo, 21:473-480, 1997.

EMPRESA BRASILEIRA DE PESQUISA AGROPECUÁRIA EMBRAPA. Manual de métodos de análise de solo. Rio de J aneiro, Serviço de Produção de Informação, 1997. 212p.

GEE, G.W. \& BAUDER, J . Particle-size analysis. In: KLUTE, A., ed. Methods of soil analysis. 2.ed. Madison, American Society of Agronomy, 1986. p.383-412.

HILLEL, D. Environmental soil physics. San Diego, Academic Press, 1998. 771p.

KEMPER, W.D. \& CHEPIL, W.S. Sizedistribution of aggregates. In: BLACK, C.A.; EVANS, D.D.; WHITE, J.L.; ENSMINGER, L.E. \& CLARCK, F.E., eds. Methods of soil analysis. Madison, American Society of Agronomy, 1965. p.499-510.

KEMPER, W.D.; ROSENAU, R.C. \& DEXTER, A.R. Cohesion development in disrupted soils as affected by clay and organic matter content and temperature. Soil Sci. Soc. Am. J ., 51:860-867, 1987.

KUNZE, G.W. \& DIXON, J .B. Pretreatment for mineralogical analysis. In: KLUTE, A. ed. Methods of soil analysis. 2.ed. Madison, American Society of Agronomy, 1986. p.91-99.

LIMA, C.L.F.; PAULETTO, E.A.; GOMES, A.S. \& SILVA, J .B. Estabilidade de agregados de um Planossolo sob diferentes sistemas de manejo. R. Bras. Ci. Solo, 27:199-205, 2003.

MAGALHÃES, A.F. \& PAGE, A.L. Características das cargas elétricas dos solos da Zona da Mata de Pernambuco. I Determinação das cargas de superfície. R. Bras. Ci. Solo, 8:173-177, 1984

MEKARU, T. \& UEHARA, G. Anion adsorption in ferruginous tropical soils. Soil Sci. Soc. Am. Proc., 36:296-300, 1972.

MENDES, I.C.; SOUZA, L.V.; RESCK, D.V.S. \& GOMES, A.C. Propriedades biológicas em agregados de um Latossolo Vermelho-Escuro sob plantio convencional e direto no Cerrado. R. Bras. Ci. Solo, 27:435-443, 2003.

MONEGAT, C. Plantas de cobertura de solo: características e manejo em pequenas propriedades. Chapecó, Edição do autor, 1996. 337p.

MORELLI, M. \& FERREIRA, E.B. Efeito do carbonato de cál cio e do fosfato diamônico em propriedades eletroquímicas e físicas de um Latossolo. R. Bras. Ci. Solo, 11:1-6, 1987.

MUNNER, M. \& OADES, J.M. The role of Ca-organic interactions in soil aggregate stability. III. Mechanics and models. Aus. J . Soil Res., 27:411-423, 1989.

OLIVEIRA, G.C.; DIAS J UNIOR, M.S.; RESCK, D.V.S. \& CURI, N. Caracterização química e físico-hídrica de um Latossolo Vermelho após vinte anos de manejo e cultivo do solo. R. Bras. Ci. Solo, 28:327-336, 2004.

PALADINI, F.L.S. \& MIELNICZUK, J . Distribuição do tamanho dos agregados de um solo Podzólico Vermelho-Escuro afetado por sistemas de culturas. R. Bras. Ci. Solo, 15:135140, 1991. 
SANTA CATARINA. Gabinete de Planejamento e Coordenação Geral. Atlas de Santa Catarina. Rio de J aneiro, Aerofoto Cruzeiro, 1986. 173p.

SAS INSTITUTE. STAT Procedures Guide for Personal Computers. Version 6. 3.ed. Cary, 1990. 705p.

SCHICK, J .; BERTOL, I.; BATISTELA, O. \& BALBINOT J UNIOR, A.A. Erosão hídrica em Cambissolo Húmico alumínico submetido a diferentes sistemas de preparo e cultivo do sol o: I- Perdas de solo e água. R. Bras. Ci. Solo, 24:427-436, 2000.

SIDIRAS, N.; VIEIRA, S.R. \& ROTH, C.H. Determinação de algumas características físicas de um Latossolo Roxo distrófico sob plantio direto e preparo convencional. R. Bras. Ci. Solo, 8:265-268, 1984.

SILVA, I.F. \& MIELNICZUK, J. Avaliação do estado de agregação do solo afetado pelo uso agrícola. R. Bras. Ci. Solo, 21:313-319, 1997.
SILVA, M.L.N.; BLANCANEAUX, P.; CURI, N.; LIMA, J .M.; MARQUES, J J .G.S. M. \& CARVALHO, A.M. Estabilidade e resistência de agregados de um Latossolo VermelhoEscuro cultivado com sucessão milho-adubo verde. R. Agropec. Bras., 33:97-103, 1998.

SPAGNOLLO, E.; BAYER, C.; WILDNER, L.P.; ERNANI, P.R.; ALBUQUERQUE， J.A. \& MENDONÇA, M.M. Leguminosas estivais intercalares ao milho como fonte de nitrogênio para o milho, no sul do Brasil. R. Bras. Ci. Solo, 26:417-423, 2002.

TEDESCO, M.J .; GIANELLO, C.; BISSANI, C.A.; BOHNEN, H. \& VOLKWEISS, S. Análise de solo, plantas e outros materiais. Porto Alegre, Universidade Federal do Rio Grande do Sul, 1995. 174p.

TISDALL, J .M. \& OADES, J .M. Organic matter and waterstable aggregates in soils. J. Soil Sci., 33:141-163, 1982.

WHITTIG, L.D. \& ALLARDICE, W.R. X-ray diffraction techniques. In: KLUTE, A. ed. Methods of soil analysis. 2.ed. Madison, American Society of Agronomy, 1986. p.331-362. 